\title{
Mangafodipir trisodium: review of its use as an injectable contrast medium for magnetic resonance imaging
}

This article was published in the following Dove Press journal:

Reports in Medical Imaging

9 July 2009

Number of times this article has been viewed

\section{Daniele Regge' \\ Stefano Cirillo' \\ Annalisa Macera' \\ Giovanni Galatola ${ }^{2}$}

'Radiology Unit, ${ }^{2}$ Gastroenterology Unit, Institute for Cancer Research and Treatment, Candiolo, Turin, Italy

Correspondence: Daniele Regge Institute for Cancer Research and Treatment, Strada Provinciale n 142, Km 3,95, Candiolo PC 10060, Torino, Italy Email daniele.regge@ircc.it

\begin{abstract}
Mangafodipir trisodium is a hepatobiliary contrast agent, taken up by the hepatocytes and largely excreted via the bile ducts. The agent increases the signal intensity of the normal liver, and to a lesser extent of the pancreas, adrenal glands, kidneys and myocardium, on T1-weighted imaging. The increase of the signal intensity on the T1 images allows better visualization of focal lesions, especially of those that are of non-hepatocitary origin such as metastases. For this reason the most important indication for the use of mangafodipir trisodium is in detecting liver metastases, especially when the information may influence therapeutic planning, which in many cases is surgical resection. New data show that this liver-specific contrast agent is accurate in detecting small lesions and in assessing the liver status following neoadjuvant chemotherapy, where other imaging techniques, such as CT and PET, fail. Other lesser indications for studies with mangafodipir trisodium are: in characterizing liver and pancreatic lesions; in identifying biliary leakage following bile duct and/or liver surgery; and possibly in the future in the assessment of the extent of myocardial damage.
\end{abstract}

Keywords: mangafodipir trisodium, magnetic resonance imaging, contrast agent

\section{Introduction}

The magnetic resonance (MR) contrast agents have been developed to improve the detection and characterization of liver lesions, and they are classified into five classes: extracellular agents, reticuloendothelial agents, hepatobiliary agents, blood pool agents, and combined agents.

The commonest and most frequently used agents for obtaining imaging of the liver are low-molecular-weight gadolinium (Gd) chelates belonging to the class of extracellular agents. They make it possible to carry out multiphase hepatic MR studies (CE-MRI) of the arterial and venous phases, thus rendering a detailed map of the intrahepatic vascular tree and providing some degree of characterization of different lesions according to the different behavior of their blood supply and wash-out. The differences in signal intensity between a focal lesion and the surrounding normal parenchyma that is obtained using these extracellular agents is, however, not always optimal.

To overcome the limitations of the low-molecular-weight Gd chelates, a new class of contrast agents has been developed specifically for liver imaging. The two main groups of contrast agents in this liver specific class are superparamagnetic iron oxides (SPIO), taken up via the reticulo-endothelial system (RES) mainly into the liver and the spleen, and hepatobiliary contrast agents, taken up mainly by the hepatocytes

submit your manuscript | www.dovepress.com 
and largely excreted via the bile ducts. Three hepatobiliary contrast agents have been approved for clinical use, and are commercially available: mangafodipir trisodium (Teslacan ${ }^{\circledR}$; GE Healthcare Milwaukee, WI, USA), gadobenate dimeglumine (MultiHance ${ }^{\circledR}$; Bracco Imaging S.p.a., Milan Italy) and gadoxate (Primovist ${ }^{\circledR}$; Bayer Schering Pharma AG, Berlin, Germany). Although these agents differ in the way they characterize and detect various liver lesions, ${ }^{1}$ all of them produce a strong increase in the signal intensity of the liver, bile ducts and of some hepatocyte-containing lesions at the T1-weighted imaging. ${ }^{2}$ Mangafodipir trisodium is a manganese (Mn) chelate [manganese (II)- $N, N$-dipyridoxylethylenediamine- $N$, $N$ '-diacetate-5,5'-bis(phosphate) sodium salt], which has been developed as a MR contrast agent designed to study the hepatobiliary system. It consists of the organic ligand fodipir (DPDP) and Mn. Mn binds to the plasma proteins and is rapidly cleared from the blood. The uptake occurs mainly in the liver, and to a lesser degree in the pancreas, adrenal glands, kidneys and myocardium. ${ }^{3}$

The aim of this review is to provide information on the properties, development and clinical applications of mangafodipir trisodium.

\section{Properties}

Following intravenous administration, mangafodipir is metabolized by dephosphorylation to Mn-DPMP and Mn-PLED, then transmetallated by zinc ( $\mathrm{Zn})$ to the corresponding compounds. ${ }^{4} \mathrm{Mn}^{2+}$ ions released from mangafodipir trisodium are most probably bound by alpha2-macroglobulin and transported to the liver, although the chemical similarity of DPDP to vitamin B6 may also contribute to the uptake by the hepatocytes. ${ }^{5}$ The agent increases the signal intensity of the liver, bile ducts and some hepatocyte-containing lesions at the T1-weighted imaging. Due to the presence of five unpaired electrons, $\mathrm{Mn}$ is moderately paramagnetic, thus determining a shortening of the $\mathrm{T} 1$ and $\mathrm{T} 2$ relaxation times of water protons. $\mathrm{T} 1$ shortening predominates at low Mn concentrations and results in a high signal intensity on the T1-weighted images; T2 shortening predominates at high concentrations, resulting in a low signal intensity on the T2-weighted images. ${ }^{2} \mathrm{~T} 1$ relaxivity of mangafodipir in aqueous solution is similar to that of $\mathrm{Gd}$; however, because of the intracellular uptake of $\mathrm{Mn}^{2+}$, its $\mathrm{T} 1$ relaxivity in the liver tissue is three times greater than that of $\mathrm{Gd} .^{5}$

Extrahepatic uptake is observed when some of the Mn dissociates from its ligand within the blood circulation. Uptake of free $\mathrm{Mn}^{2+}$ ions occurs in the pancreas, heart and liver through nonspecific transport mechanisms. ${ }^{2}$
Biodistribution studies in rats have shown that 30 minutes after injection, $13 \%$ of mangafodipir trisodium is present in the liver, $9 \%$ in the small intestine, $3 \%$ in the blood, $1.3 \%$ in the kidneys and less than $1 \%$ in various other locations. ${ }^{5}$

The recommended adult dose of mangafodipir is $5 \mu \mathrm{mol} / \mathrm{kg}$ body weight, which corresponds to $0.5 \mathrm{~mL} / \mathrm{kg}^{6}{ }^{6}$ The dose is administered with a relatively slow intravenous injection over 10 to 20 minutes. Hepatic enhancement begins at approximately one minute after administration, peaks at approximately 15 minutes, and persists for several hours. ${ }^{1}$ Elimination occurs mainly through the biliary system. Within 5 days $59 \%$ of mangafodipir is excreted via the bile ducts, while only $15 \%$ is eliminated through the kidneys in the first 24 hours. $^{7}$ Renal excretion is enhanced in patients with hepatic insufficiency. Biliary excretion can be seen starting 5 minutes after injection; complete delineation of the biliary system may require more than 15 minutes. ${ }^{8,9}$

The chemical toxicity of mangafodipir has been studied in detail. ${ }^{10} \mathrm{Mn}$ is an essential trace metal in humans whose normal whole body content is 12 to $20 \mathrm{mg}$. Although the intravenous dose of Mn ions after administration of mangafodipir is close to the total whole body amount of Mn and far exceeds the recommended daily supplementation of $\mathrm{Mn}$, no acute or subchronic toxicity has ever been observed. ${ }^{5,10}$ The LD50 (lethal dose, which kills $50 \%$ of the animals) of mangafodipir in mice was $5.4 \mathrm{mmol} / \mathrm{kg}$, compared to 5.5 to $10 \mathrm{mmol} / \mathrm{kg}$ for Gd-DTPA. ${ }^{5}$ The range of safety, as expressed by the ratio of LD50 to the dose used for imaging, is 540 for mangafodipir and 60 to 100 for Gd-DTPA. ${ }^{5}$ In phase 1 to 3 studies, both on normal volunteers and patients, several adverse events have been observed with variable frequency: warmth/flush, nausea, heart pounding (increase in blood pressure and heart rate) and dizziness. ${ }^{5}$ In a phase 2 study, $55 \%$ of patients experienced facial flushing; mild to moderate nausea was observed in 9\%. ${ }^{11} \mathrm{~A}$ transient increase in blood pressure and heart rate occurred immediately after injection, but returned to baseline after 5 minutes in all patients. In a European phase 3 study, 14 of 82 patients (17\%) experienced adverse events other than discomfort. ${ }^{12}$ In a second phase 3 study, only $2.5 \%$ of patients reported facial flush and $1.7 \%$ mild adverse events other than flush. ${ }^{13}$ Bernardino et $\mathrm{al}^{11}$ reported that facial flushing was referred more often after rapid intravenous bolus injection than after slow infusion. However, facial flushing was not significantly increased when a slow bolus injection was performed over a 2- to 2.5-minute period, by comparison with a slow infusion over a period of 10 to 20 minutes; the latter is the suggested way of administering mangafodipir in Europe. ${ }^{14}$ 
Postcontrast imaging may start as soon as maximal enhancement is achieved, usually around 20 minutes after the beginning of the intravenous infusion; however, longer delays are possible because liver parenchyma enhancement persists for a long time.

Mangafodipir is labeled a class $\mathrm{C}$ drug and should not be administered to pregnant woman. Also, the effect of the mangafodipir excreted in breast milk on breast-fed infants is unknown.

\section{Clinical developments Detection of liver metastases}

Liver is the most common site of metastatic cancer seeding. ${ }^{15}$ Liver metastases can be treated using many different strategies, including mainly surgery, chemotherapy, radiotherapy, selective arterial injection of cytotoxic agents with or without embolization, and ablation via percutaneous access, aiming either at a curative or palliative intent. The choice of the optimal strategy depends on the general clinical data, but is mainly decided by an accurate assessment of the imaging characteristics of both the liver and the lesions, including their number, size and location, type of tissue, and the number of involved liver segments. ${ }^{16}$ A detailed mapping of metastatic liver involvement is therefore essential to establish the most adequate and effective treatment.

Lesion-to-liver contrast is significantly improved by the administration of mangafodipir, resulting in higher detection rates with respect to conventional imaging techniques (Figure 1). In a European phase 3 trial, mangafodipirenhanced MRI identified a greater number of lesions than unenhanced MRI in $22 \%$ to $36 \%$ of patients; in the same study, by comparison with contrast enhanced computed tomography (CT), mangafodipir-enhanced MRI identified a greater number of lesions in $31.1 \%$ of the cases, and fewer lesions in $13.4 \% .{ }^{13}$ In the US phase 3 trial, mangafodipirenhanced MRI was comparable or superior to CT. ${ }^{17}$ As a limit of both studies, not all patients underwent spiral CT.
A

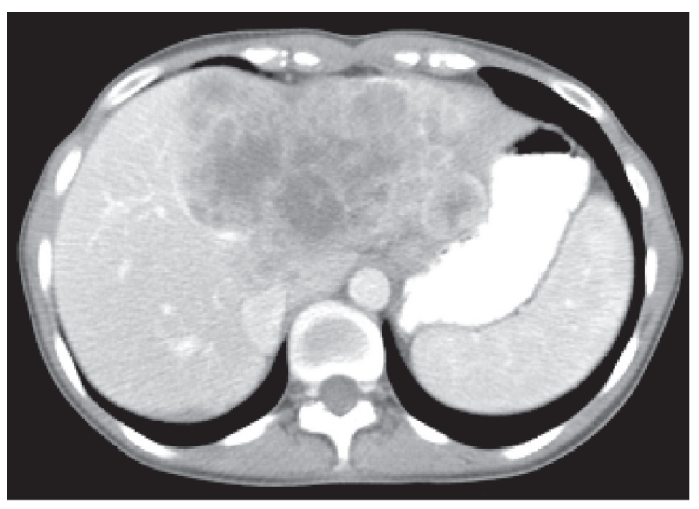

C

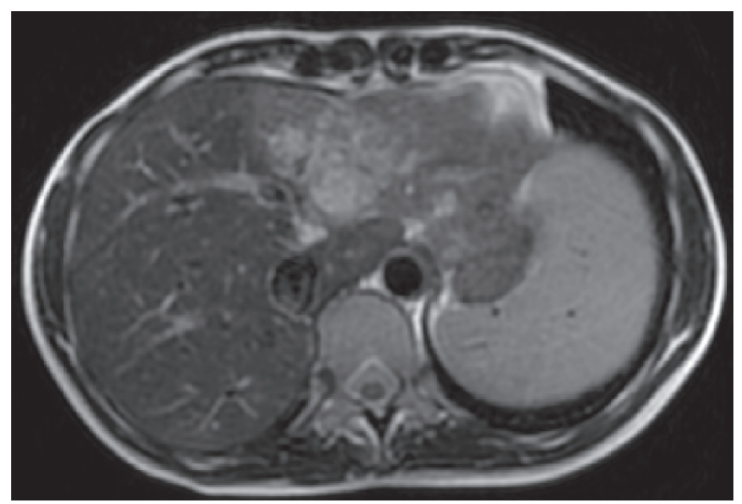

B

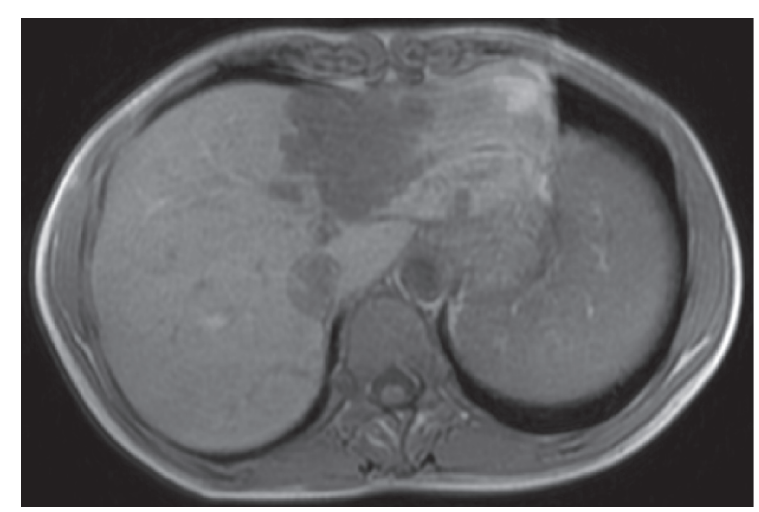

D

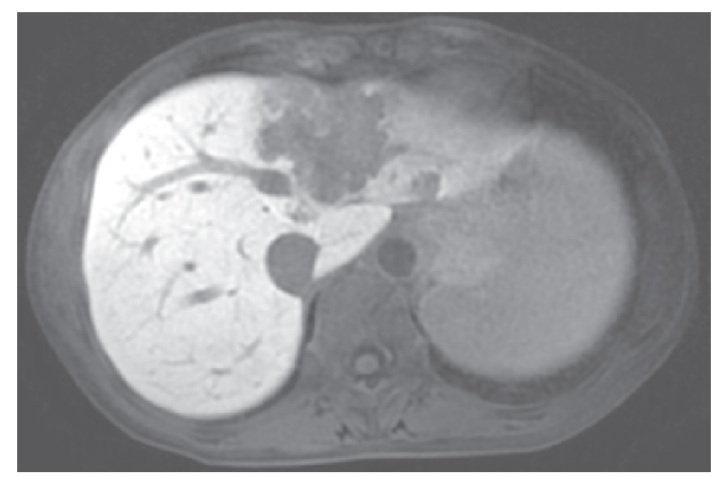

Figure I Large colorectal cancer liver metastasis involving most of the left liver lobe. (A) The CT scan shows a large, hypodense, inhomogeneous mass. (B) The lesion is hypointense on the TI-weighted image and (C) slightly hyperintense and inhomogeneous on the T2-weighted scan. (D) At mangafodipir-enhanced MRI the metastasis is very hypointense and has well defined margins with respect to the normal hepatic parenchyma. 
There is evidence that mangafodipir-enhanced MRI is likely to influence the operative decision in candidates to surgical resection of liver metastases by detecting small lesions that were not shown at CT scan. In 2004, Bartolozzi et al ${ }^{18}$ presented the results of a prospective, multi-institutional trial, whose primary end-point was to compare the sensitivity of unenhanced and mangafodipirenhanced MRI with that of spiral CT scan in the detection of liver metastases from colorectal cancer (CRC). The authors used as the standard of reference intraoperative ultrasound (IOUS), which detected a total of 128 metastatic lesions, ranging from 0.2 to $12.0 \mathrm{~cm}$ in diameter. Forty-seven of the 128 lesions were $\leq 1 \mathrm{~cm}$ in diameter; 31 ranged from 1.1 to $2 \mathrm{~cm}$, and 45 were $>2 \mathrm{~cm}$. Histological confirmation of the metastases was obtained in the 89 of 128 lesions that were surgically removed; the remaining 39 lesions underwent intra-operative radio-frequency thermal ablation. Results from the per-lesion analysis showed an overall detection rate of $71 \%$ (91 of 128 lesions) for spiral CT, $72 \%$ (92 of 128) for unenhanced MRI, and 90\% (115 of 128) for mangafodipir-enhanced MRI. The latter was signifcantly more sensitive than both unenhanced MRI $(P<0.0001)$ and spiral CT $(P=0.0007)$. The difference in sensitivity of mangafodipir-enhanced MRI versus spiral $\mathrm{CT}$ and unenhanced MRI was even more significant for lesions $\leq 1 \mathrm{~cm}$ in their largest diameter. Finally, all lesions undetected by mangafodipir-enhanced MRI and discovered at the time of surgery by IOUS did not exceed $1 \mathrm{~cm}$ in diameter (Figure 2).

Kim et a ${ }^{19}$ evaluated 69 patients with colorectal cancer, finding a total of 181 liver lesions, both benign and malignant, ranging from 0.2 to $12.5 \mathrm{~cm}$ in largest diameter.
The authors did not find significant differences between the detection rate of mangafodipir-enhanced MRI and that of helical CT, whether considering all the hepatic lesions or only the metastases ( $P=0.383$ and 0.143 , respectively). However, if only small $(\leq 2 \mathrm{~cm})$ hepatic metastases were considered, then the detection rate of mangafodipir-enhanced MRI was significantly higher than that of helical CT both overall $(P=0.022)$ and for those with histopathologic confirmation $(P=0.043)$.

In our experience, mangafodipir was very accurate in detecting liver metastases in patients with colorectal cancer. ${ }^{20}$ We reviewed the findings of spiral CT and mangafodipirenhanced MRI in 125 consecutive patients undergoing surgery for primary or metastatic disease, for a total of 192 lesions. Sixty-two of the 125 patients had at least 1 liver metastasis; in the remaining 63 patients no lesions were detected at IOUS. The per-patient diagnostic accuracy and sensitivity of mangafodipir-enhanced MRI were significantly higher than those of spiral CT in the detection of liver metastases from colorectal cancer, the difference being most evident for lesions with $\mathrm{a} \leq 1 \mathrm{~cm}$ largest diameter. In this group spiral CT, unenhanced MRI and enhanced MRI detected respectively 31 (48\%), 35 (54\%) and 44 (68\%) of the 65 metastases.

Koh et $\mathrm{a}^{21}$ compared the sensitivity and specificity of mangafodipir alone with the diffusion weighted imaging (DWI) with or without mangafodipir in 38 patients and a total of 133 lesions ( 83 metastases, 49 cysts and 1 hemangioma). The authors demonstrated that the best results are obtained by combining the two sequences. A possible explanation may be due to the fact that on the one hand DWI overcomes the limitations of mangafodipir in detecting small metastases

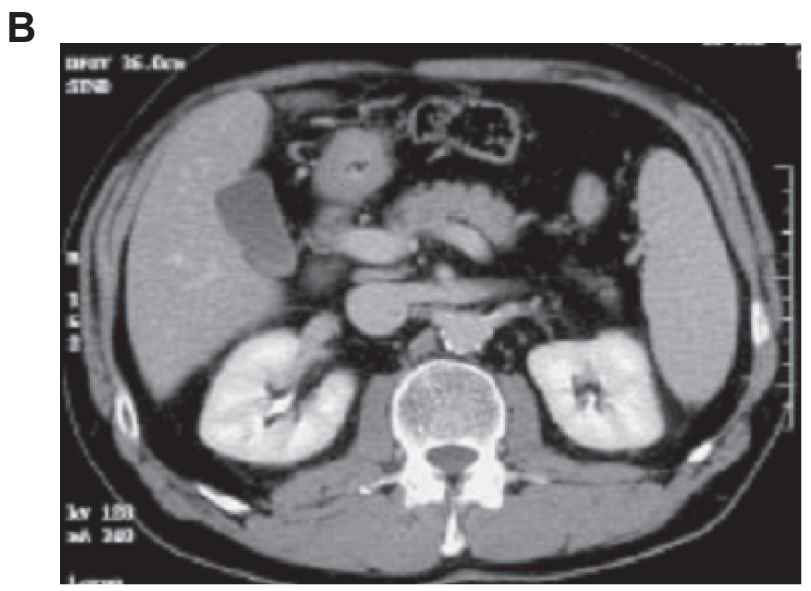

Figure 2 Small superficial colorectal cancer metastasis. (A) Mangafodipir-enhanced MRI shows a small subcapsular lesion of the 6th hepatic segment (arrow) that (B) was not detected at CT. 
placed near vascular structures, and on the other mangafodipir improves the detection of lesions obscured by DWI because of cardiac motion and susceptibility effects.

Sahani et al $^{22}$ compared high-spatial-resolution mangafodipir trisodium-enhanced liver MRI and wholebody FDG-PET (fluorodeoxyglucose-positron emission tomography) in 30 patients with colorectal cancer and pancreatic adenocarcinoma, with a total of 79 liver metastases. FDG-PET provided additional information about extrahepatic disease and was useful in the initial cancer staging. The per-patient analysis showed that sensitivity, positive predictive value and diagnostic accuracy of MRI in detecting liver metastases were $96.6 \%, 100 \%$, and $97.1 \%$, respectively versus $93.3 \%, 90.3 \%$ and $85.3 \%$ respectively for FDG-PET. MRI detected more hepatic metastases than FDG-PET $(P=0.016)$; all of the 33 lesions measuring $<1 \mathrm{~cm}$ and confirmed at the reference standard were identified by MRI, whereas only 12 were detected by FDG-PET $(P=0.0001)$.

\section{Evaluation of liver metastases following neoadjuvant chemotherapy}

One of the potential applications of contrast enhanced MRI is to assess the extent of metastatic liver disease in patients following neoadjuvant chemotherapy (CHT). In this group of patients, liver imaging is essential to assess both the treatment response and the surgical resectability of the metastases. Two studies have shown that $15 \%$ to $20 \%$ of patients become operable following CHT, thus offering to them the only available curative treatment. ${ }^{23,24}$ Furthermore, even though IOUS is very accurate in detecting liver lesions, pre-operative liver imaging accurately localizes the metastases in the liver, allowing the surgeon to plan the intervention and avoid unnecessary removal of excessive liver parenchyma.

The detection of liver metastases at CT is more difficult following $\mathrm{CHT}^{25}$ Although this may occur because the lesions have decreased in size and are less conspicuous, there is the possibility that they become difficult to detect because of drug-induced steatosis, which modifies the density of normal liver parenchyma. We have recently evaluated the diagnostic accuracy of spiral CT and mangafodipir MRI in detecting liver metastases from colorectal cancer in a series of patients undergoing surgery following neoadjuvant CHT. ${ }^{26}$ The study group included 36 patients (14 females and 22 males, median age $=61.1$ to $11.46 \mathrm{SD}$ ) with a total of 132 lesions. The standard of reference was histology of the surgically excised lesions, or IOUS in the cases where pathological assessment was not possible. We used a 16-slice CT scanner and a 1.5 Tesla MRI unit. The per-lesion sensitivity, specificity and accuracy were, respectively: $64.5 \%$ (69/107), 36\% (9/25) and 59.1\% (78/132) for CT and 83.2\% $(89 / 107), 40 \%(10 / 25)$ and $75 \%(99 / 132)$ for mangafodipir MRI. Sensitivity and accuracy were significantly higher for MRI with tissue-specific agent by comparison with CT ( $P=0.0023$ and $P<10^{-3}$ respectively).

There are no published studies comparing the detection of liver metastases by FDG-PET and MRI with tissue specific agent in patients undergoing neoadjuvant treatment. However, a recent paper by Nir Lubezky et $\mathrm{al}^{25}$ compared the detection rate of metastases by FDG-PET, using MDCT (multidetector CT) as a reference standard, in order to assess its diagnostic value. Interestingly, while FDG-PET was superior to CT in the detection of liver metastases of non-treated patients $(93.3 \%$ versus $87.5 \%$, $P<0.0001$ ), its sensitivity following CHT dropped dramatically to almost half the values, being far lower than CT (49\%, versus $65.3 \%$ for MDCT, $P<0.0001)$. Failure of FDG-PET to detect metastases following CHT may be due to the shut down effect of CHT on cellular metabolism, on the low spatial resolution of the test, on the time interval between the FDG-PET and surgery and on the fact that some tumors become metabolically "non-avid" of glucose; ${ }^{25}$ it has been reported that FDG-PET has a poor sensitivity for mucinous adenocarcinoma, and therefore liver metastases from this tumor may fail to be visualized by the test.

\section{Changes in intraoperative staging and $M R I$ as prognostic factor}

Staging with IOUS is more accurate than preoperative evaluation with $\mathrm{CT}$ and MRI. Additional metastases have been found in $22.8 \%$ of patients when preoperative staging was performed with single-slice helical CT and MRI without the use of extracellular agents. ${ }^{27}$

A recent work by Tamandl et $\mathrm{al}^{28}$ has evaluated the role of contrast enhanced MDCT and MRI with specific agents in the preoperative assessment of liver metastases, giving a different perspective on the role of imaging in the surgical planning. The authors reviewed data from 194 consecutive liver resections in patients with liver metastases from colorectal cancer, with a total of 408 lesions; MDCT and MRI with hepatospecific agent (either mangafodipir or gadoxate) were performed in all the cases prior to surgery. Images were routinely evaluated and reviewed by attending radiologists with a great expertise in hepatobiliary diagnostics and results were regularly discussed at weekly 
multidisciplinary meetings with liver surgeons, medical oncologists, radiologists, and radiation oncologists.

Additional lesions were detected intraoperatively in only 16 of the 194 patients (8.2\%); in 11 cases (5.7\%) the lesions were $<1 \mathrm{~cm}$ and subcapsular. Even though all additional lesions were removed, detection of additional tumors was associated with a shorter median recurrence-free survival. The authors concluded that preoperative imaging with contrast enhanced MDCT and MRI with liver-specific contrast agent is efficient and very seldom leads to a change in the surgical strategy, and that patients with additional resectable liver metastases have a higher risk of recurrence and should be monitored carefully.

\section{Characterization of liver lesions}

\section{Liver metastases}

By comparison with the normal hepatic tissue, metastases usually produce a low signal intensity on unenhanced T1-weighted MR images and a moderately high signal on unenhanced T2-weighted images. ${ }^{29}$

The vast majority of liver metastases do not take up liverspecific contrast agents, including mangafodipir. ${ }^{30}$ Therefore, as reported in the previous section, an increase in the liverto-lesion and contrast-to-noise ratios are observed, allowing a better identification of lesions. ${ }^{31-33}$ A peripheral rim of enhancement, or a wedge shaped enhancement has been occasionally observed both in the early phase (20 minutes following contrast administration) and in delayed imaging (4 to 24 hours following contrast administration) (Figure 3). The peripheral enhancement involves the normal liver parenchyma and is probably due to compression secondary to the tumor growth, that determines a functional biliary obstruction with a subsequent retention of the contrast agent.

Mangafodipir may be useful to distinguish metastases from benign lesions, such as focal nodular hyperplasia (FNH), and from well-differentiated hepatocellular carcinoma (HCC), that take up the contrast agent. ${ }^{34}$ Other nonhepatocellular liver lesions, such as hemangiomas and cysts, also do not show an uptake of the contrast agent and the peripheral rim enhancement is rarely seen, because of their slow growth. ${ }^{35}$ However, differentiation between cysts or hemangiomas and metastases is primarily based on T2-weighed pulse sequences, where the former lesions appear highly hyperintese. Enhancement of neuroendocrine tumor metastases has been described rarely. ${ }^{35}$ The pathophysiology of enhancement of these metastases has not been clarified, but it may be related to the increased metabolism of these tumors.

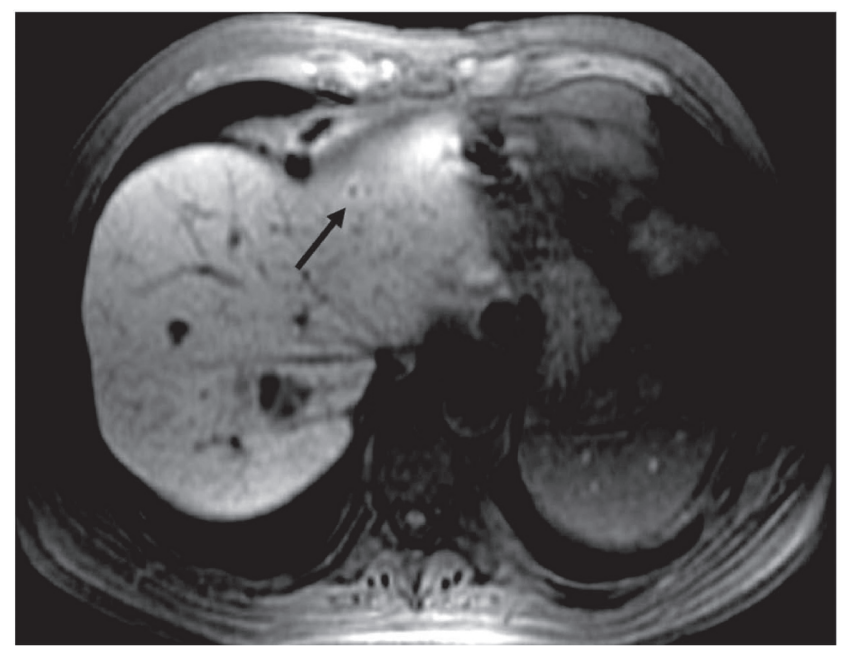

Figure 3 Image shows a small colorectal cancer metastasis of the second segment, with a thin peripheral rim of enhancement (arrow).

\section{Hepatocellular carcinoma (HCC)}

HCC is the most common primary liver neoplasm. ${ }^{36}$ Long-standing cirrhosis, induced mainly by chronic hepatitis $\mathrm{B}$ or $\mathrm{C}$ viral infections or to abuse of alcohol intake, is the main cause of HCC. ${ }^{37}$ At the time of diagnosis HCC may present itself as a solitary nodule in approximately $50 \%$ the cases, it is multifocal in $40 \%$ and diffuse in less than $10 \%$ of the cases. In $50 \%$ to $80 \%$ of the cases a thin pseudo-capsule surrounding the tumor can be seen using the various imaging techniques. ${ }^{38}$ The MR appearance of HCC is variable depending on its degree of differentiation. Poorly differentiated lesions are typically moderately hypointense on T1-weighted images and mildly hyperintense on T2-weighted images; ${ }^{38}$ well-differentiated lesions are isointense on both T1- and T2-weighted images. ${ }^{38}$

HCC shows a considerable variability in the uptake of liver-specific contrast agents depending on the amount of functioning hepatocytes. Well-differentiated HCC usually show a significant uptake of the contrast agent; ${ }^{39,40}$ sometimes enhancement is greater than the surrounding parenchyma. However, well-differentiated nodules do not always behave in the same way; sometimes enhancement is heterogeneous and with capsular sparing. ${ }^{41}$ Undifferentiated or poorly differentiated HCC usually show only minimal or no enhancement after mangafodipir administration, because of the lack of functioning hepatocytes (Figure 4). ${ }^{41}$

Occasionally, well-differentiated or moderately differentiated nodules may appear highly hyperintense in the delayed T1-wheighted post-contrast images. ${ }^{42}$ These lesions, sometimes termed green hepatomas, show a high concentration of biliary pigments within the cytoplasm of 
A

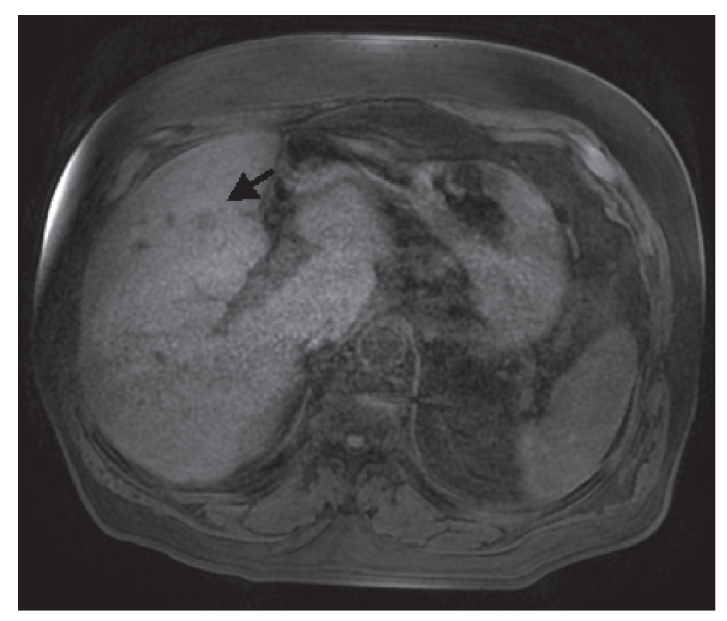

B

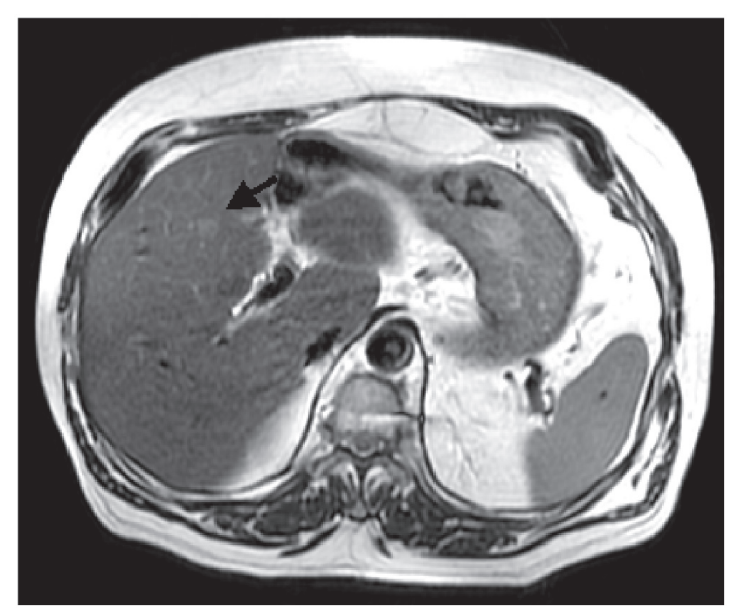

\section{C}

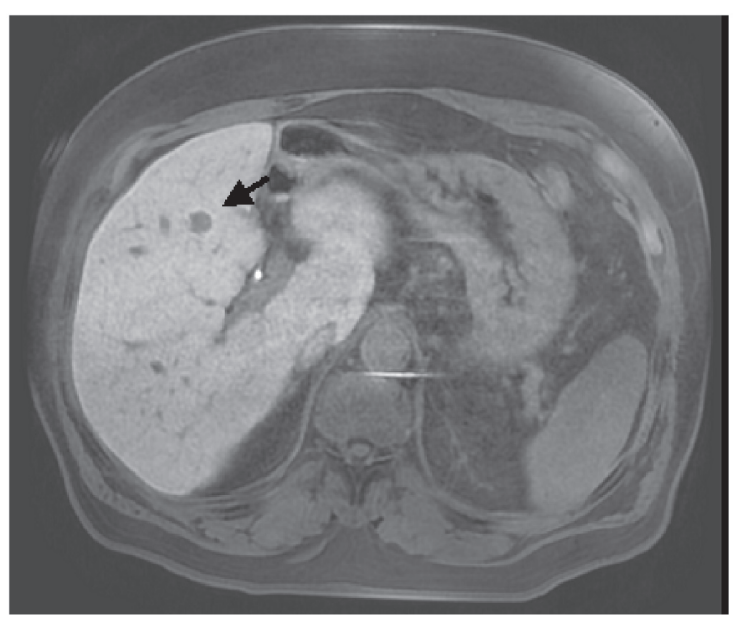

Figure 4 Poorly differentiated hepatocellular carcinoma. (A) The unenhanced TI-weighted image shows a slightly hypointense lesion of the 4th hepatic segment (arrow) that is (B) slightly hyperintense at T2-weighted imaging (arrow). (C) The lesion is markedly hypointense at TI-weighted imaging following mangafodipir infusion (arrow). the hepatocytes. Differentiation of dysplastic liver nodules from well-differentiated HCC is not possible with liverspecific contrast agents, because both lesions show similar degrees of contrast agent uptake. ${ }^{43,44}$

Evaluation of the liver in patients with chronic liver diseases is still a major diagnostic challenge, as the uptake of mangafodipir and its metabolism are related to the liver cell function. ${ }^{40,45-49}$ In animal studies, after the administration of mangafodipir trisodium, liver enhancement is reduced if chronic liver damage is present. ${ }^{50}$ Murakami et $\mathrm{al}^{48}$ showed that patients with cirrhosis have a reduced liver enhancement; as a consequence, the detection of focal lesions may be impaired. Indeed, this was demonstrated by a study from Youk et $\mathrm{al}^{47}$ who compared the detection rate of HCC using slow intravenous infusion of mangafodipir, and the extracellular contrast agent gadopentetate dimeglumine (Magnevist ${ }^{\mathbb{}}$; Shering, AG, Berlin, Germany) during multiphasic dynamic T1-weighted $3 \mathrm{D}$ imaging. The authors evaluated 46 patients with a total of 96 HCCs. The sensitivity of mangafodipir and gadopentetate dimeglumine was $72.4 \%$ and $87.5 \%$ respectively $(P<0.05)$. The reasons for the low rate of detection of HCC with mangafodipir were attributed both to the high number of isoenhanced lesions and to an abnormal liver enhancement due to hepatic dysfunction.

\section{Hemangioma}

Hemangioma is the most frequent benign liver tumor that can develop at all ages, most commonly in premenopausal women. ${ }^{51,52}$ Hemangiomas are typically asymptomatic and are usually incidental findings. At histopathology, hemangiomas are represented mainly by endothelium-lined vascular spaces separated by fibrous septa and derive their blood supply from the hepatic artery. ${ }^{52}$

On unenhanced T1-weighted images, hemangiomas are usually well defined, lobulated and hypointense nodules. On unenhanced T2-weighted images, hemangiomas appear markedly hyperintense..$^{53}$ Uptake of mangafodipir is not expected in hemangiomas, due to the lack of hepatocytes. Therefore hemangiomas are hypointense on mangafodipirenhanced images (Figure 5).

\section{Focal nodular hyperplasia (FNH)}

FNH is the second most common benign liver tumor, for which there is no surgical indication. The overall incidence of FNH is around 3\% to 5\% and this lesion is most commonly found in younger women. The histological structure of FNH is similar to that of normal hepatic parenchyma, 
A

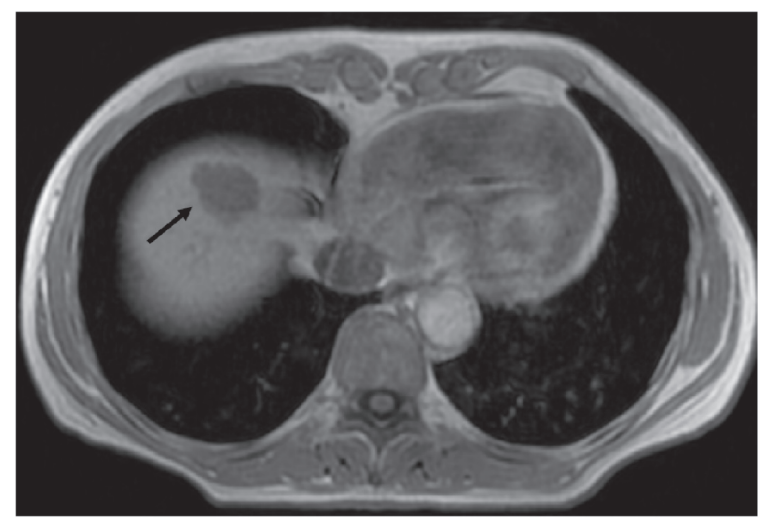

B

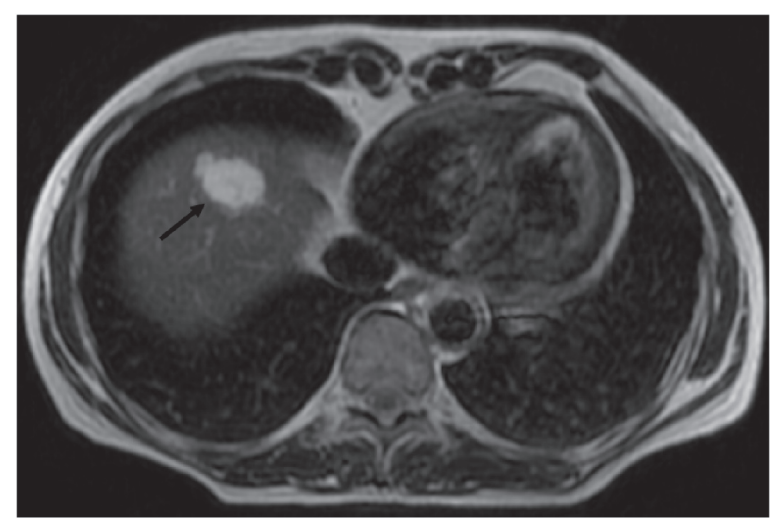

C

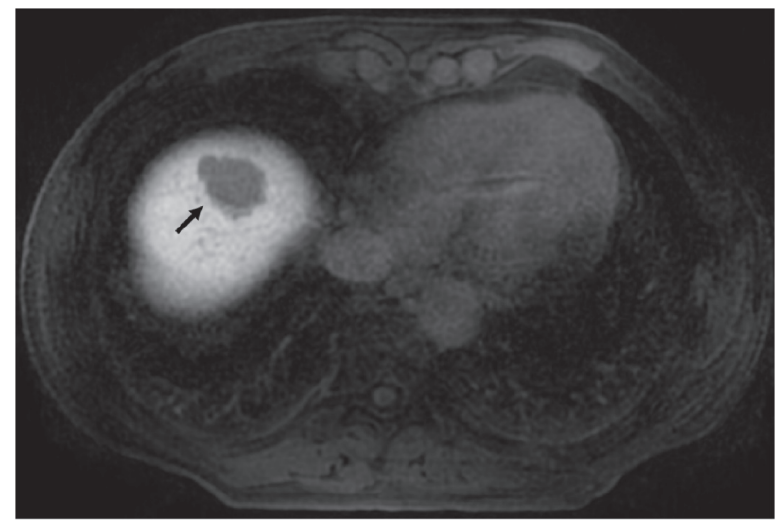

Figure 5 Liver hemangioma. (A) Focal lesion of the 8th segment, hypointense at TI-weighted imaging (arrow) and (B) markedly hyperintense at T2-weighted imaging (arrow). (C) Lesion is not enhanced by the administration of mangafodipir (arrow).

but there may be present abnormal bile ducts that are not connected to the rest of the biliary tree. ${ }^{51,54} \mathrm{FNH}$ is usually less than $5 \mathrm{~cm}$ in diameter but occasionally $>10 \mathrm{~cm}$ lesions have been observed. A thin central scar, consisting of an enlarged abnormal artery supported by a collagen infrastructure, may occasionally be recognized, especially in large nodules.

FNH is difficult to detect without administering contrast agent. On unenhanced T1-weighted MR images, the lesion is isointense or minimally hypointense with respect to the normal liver parenchyma; occasionally a hypointense central scar may be recognized in the lesion center. On unenhanced T2-weighted MR images, FNH is isointense to mildly hyperintense with an occasional hyperintense central scar. ${ }^{55}$

Typically, FNH shows a homogeneous enhancement following mangafodipir administration. FNH is isointense or slightly hyperintense compared to the surrounding parenchyma in approximately $90 \%$ of cases (Figure 6); ${ }^{55}$ when present, the central scar does not enhance after mangafodipir. Therefore the radial or spoke-wheel appearance of the central scar is better depicted on post-contrast images. ${ }^{1}$ Mangafodipir, similarly to the other liver-specific hepatic agents, is therefore of great help for confidently characterizing FNH thus avoiding unnecessary liver surgery.

\section{Hepatocellular adenoma}

Hepatic adenoma is a benign neoplasm typically found in young women taking oral contraceptives, occasionally also in men using anabolic steroids or in patients with glycogen storage diseases. ${ }^{56}$ Adenomas can regress after the cessation of oral contraceptives, although some may continue to grow and eventually bleed, which may result in a clinical presentation of acute onset right upper quadrant pain owing to intralesional hemorrhage. Since rupture and malignant transformation do occur rarely, hepatic adenomas are usually removed by surgery when they are larger than $3 \mathrm{~cm} .{ }^{57}$ Hepatic adenomas are composed of larger than normal benign hepatocytes containing glycogen and lipids, arranged in sheets and cords, and are typically 5 to $10 \mathrm{~cm}$ in diameter and surrounded by a capsule; ${ }^{51}$ they contain Kupffer cells, but in variable numbers and variably functioning. Although they contain functioning hepatocytes, they lack bile ducts and therefore bilirubin excretion is blocked. ${ }^{58}$

The appearance of hepatic adenomas on unenhanced MR imaging is variable. If the vascular support is adequate, they are usually hypointense on T1-weighted images and mildly hyperintense or isointense on T2-weighted images. However, if fat and hemorrhagic areas are present within the lesion, T1- and T2-weighted images may show inhomogeneous patterns. ${ }^{59}$ Because mangafodipir is taken up by the abnormal hepatocytes, tumors show up enhanced and they appear as 
A

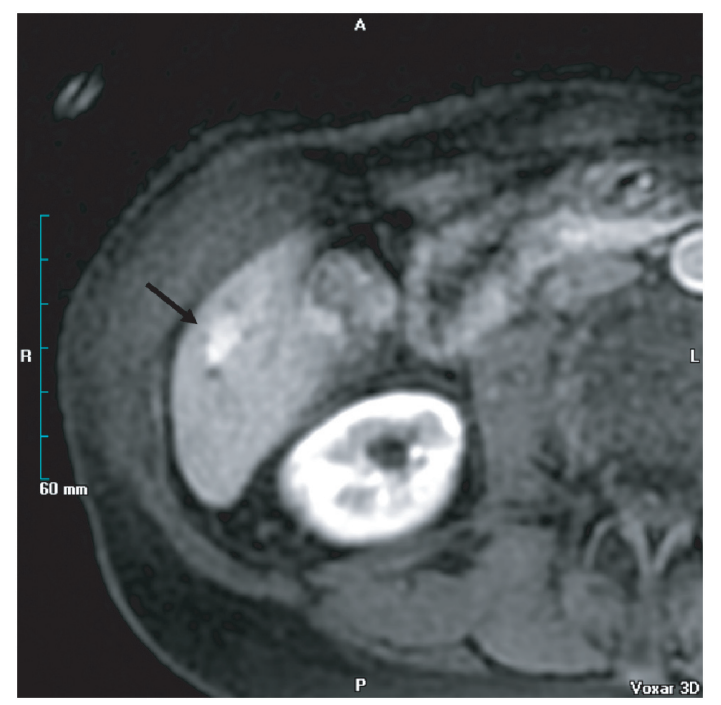

B

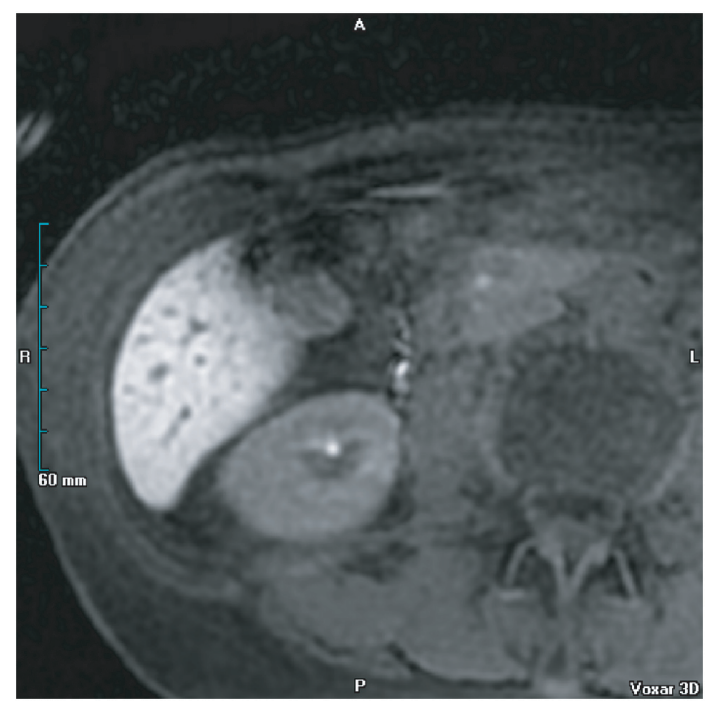

Figure 6 Small focal nodular hyperplasia. (A) TI-weighted imaging during bolus injection of extracellular agent shows a hyperenhanced focal lesion of the 5th segment (arrow). (B) Lesion is not enhanced at TI-weighted imaging following infusion of mangafodipir.

iso- or hyperintense on delayed-phase images. Therefore, by using mangafodipir it is possible to differentiate between metastases and adenomas. ${ }^{60}$

Adenomas do not have central scars, and this may help in the differential diagnosis with FNH. However, some lesions show only a negligible uptake of mangafodipir, which does not help in a reliable differentiation with HCC. ${ }^{60}$ Uncertainty is not clinically relevant in most cases, as treatment is usually required for both lesions.

\section{Fibrolamellar carcinoma}

Fibrolamellar carcinoma is a distinct subtype of HCC and is considered as a separate pathological entity for its peculiar clinical characteristics. It occurs predominantly in young adults with no underlying liver disease. Fibrolamellar carcinomas are solitary lesions and are usually diagnosed when they are large; a central star-like scar with radiating fibrous strands is commonly found within the lesion. Calcification of the scar is present in up to $50 \%$ of cases. ${ }^{61,62}$

On MRI, fibrolamellar carcinoma is heterogeneous and moderately hypointense or isointense on T1-weighted images and moderately hyperintense on T2-weighted images. The central scar is mostly hypointense on both T1- and T2-weighted images. Compared with FNH, the central scar is generally much larger, more irregular and more heterogeneous in signal intensity and contrast enhancement. With hepatocyte-specific or RES-specific contrast agents, fibrolamellar carcinoma usually does not show significant enhancement; ${ }^{6}$ this may be helpful for distinguishing this tumor from $\mathrm{FNH}$.

\section{Cholangiocellular carcinoma}

Cholangiocellular carcinoma (CCC) is the second most common form of primary hepatic malignancy and derives from the biliary epithelium. Depending on the site of origin, CCC is divided into an intrahepatic form (ICC), which accounts for approximately $50 \%$ of all the CCC, and an extrahepatic from, which accounts for the other $50 \%$ and derives from the extra-hepatic bile ducts. ${ }^{63}$

On unenhanced T1-weighted MR images, CCC has a generally iso- to hypointense signal intensity relative to the normal liver and on T2-weighted images, it has a mild to markedly increased signal intensity, depending on the amount of fibrous tissue (responsible for the lower signal intensity on T2-weighted images) and mucin content (responsible for higher signal intensity). One of the problems with hepatobiliary contrast agents in the delineation of the Klatskin tumors is their low signal intensity, which is very similar to that of the portal vein on mangafodipir enhanced MRI. In this respect, SPIO-enhanced MRI might be superior.

\section{Other uses of mangafodipir}

\section{The pancreas}

Pancreatic cancer is the fourth-leading cause of cancer death in the Western world. The prognosis is dismal, with an 
overall 5-year survival rate of approximately $5 \% .{ }^{64}$ Over the past 25 years, the radiologist's ability to diagnose pancreatic cancer has improved enormously due to the development of cross-sectional imaging techniques such as ultrasound and especially MDCT, with its capability for 3D imaging. MRI is therefore usually not routinely indicated in patients with pancreatic cancer. However, there may be cases were MRI is useful. MRI can provide a definitive diagnosis in patients with equivocal findings at ultrasound and/or CT as to the presence or absence of a tumor; it also helps providing a correct staging of the cancer in critical cases, which may help reduce the number of unnecessary laparatomies; it may also aid to differentiate cancer cases from patients with focal pancreatitis, which can often be managed conservatively. ${ }^{64}$ On unenhanced MRI, small tumors are best detected on T1-weighted breath-hold fat-suppressed gradient recalled echo (GRE) images as hypointense masses. If the tumor involves the peri-pancreatic tissues, fat-suppressed T1-weighted GRE images show a lack of contrast between the low tumor signal intensity and the suppressed background fat signal; therefore, the acquisition of T1-weighted GRE images without fat suppression is also advisable. The delineation of the tumors is difficult on T2-weighted images, as they may appear iso- or only mildly hyperintense. Mangafodipir-enhanced MR studies may help detecting tumors in difficult cases, as the tumor is markedly hypointense with respect to the normal pancreatic parenchyma (Figure 7). Liver-specific agents also provide an accurate regional staging of pancreatic cancer. In a series of 105 patients studied with mangafodipir-enhanced MRI, Schima et al ${ }^{64}$ have reported a diagnostic accuracy of over $90 \%$ for local staging of the disease. The authors concluded that mangafodipir trisodium is a versatile contrast agent for pancreas MRI as it increases the reader's confidence in the detection or exclusion of small pancreatic tumors in patients with equivocal CT findings.

Assessment of metastatic disease to the liver is an important factor in staging pancreatic cancer patients, since this event tends to occur early in patients with pancreatic tumors. As detailed previously, MRI with liver-specific contrast agents is superior to CT in the detection of liver metastases. In pancreatic cancer the most important information is to know whether the disease has spread to the liver. In fact, even if one small liver metastasis is present, the disease is considered generalized and therefore not amenable to surgical treatment. MR with liver-specific contrast agents may reveal the presence of small metastases in patients with negative CT findings. In these patients the surgical approach must be avoided; laparoscopy may be performed prior to laparatomy in order to detect and confirm histologically small metastases. ${ }^{65}$

\section{The biliary tree}

Imaging of the bile ducts with MR cholangio-pancreatography (MRCP) does not require intravenous contrast material infusion. The degree of bile duct dilatation, and the site and nature of bile duct obstruction can be readily assessed by this non-invasive and fast imaging technique. However, conventional MRCP examination does not provide information on possible biliary leakages. Leakages can occur following surgical interventions such as liver transplantation, liver resection or cholecistectomy. Ultrasound or CT can demonstrate postoperative supramesocolic fluid collections but cannot provide a direct evidence of the hyatrogenic injury. To confirm the presence of biliary leakage contrast material should be introduced in the biliary tree by direct cholangiography, either

\section{B}

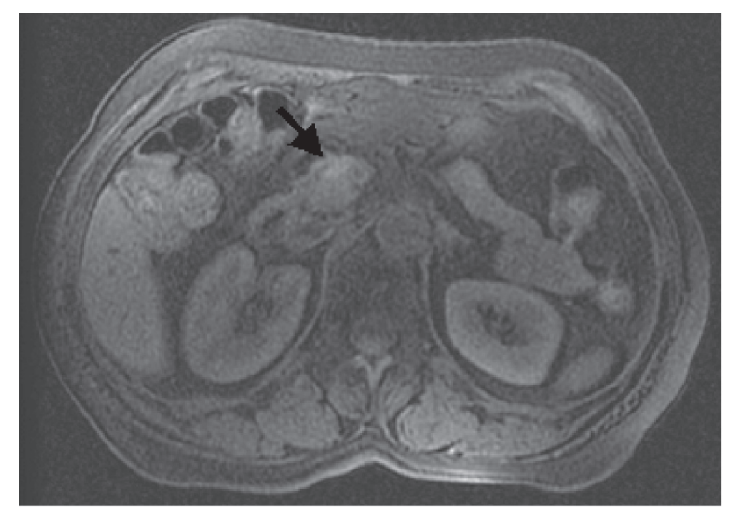

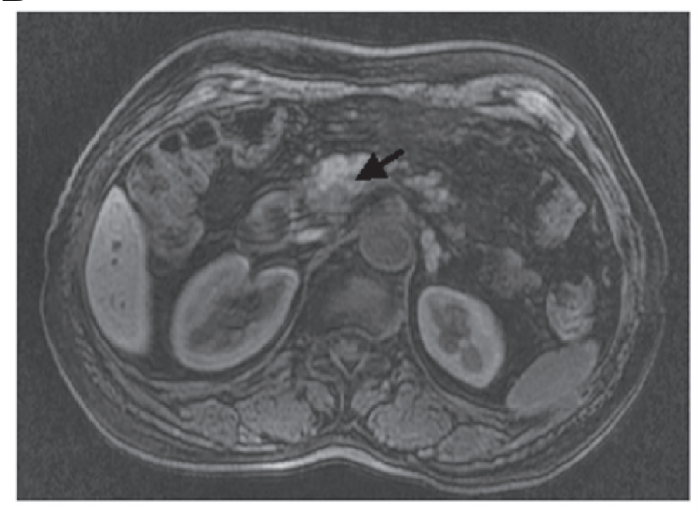

Figure 7 Small pancreatic carcinoma. (A) TI-weighted imaging shows a slightly hypointense focal lesion of the pancreatic head (arrow). (B) Axial TI-weighted scans showing that lesion visualization is improved following mangafodipir infusion (arrow). 
by retrograde approach or percutaneously. However, even using this approach a complete visualization of the biliary tree may be difficult to obtain if a stricture is present above or below the level of the leakage. ${ }^{66,67}$

Mangafodipir-enhanced MRCP was first reported by Vitellas et al in $2001 .{ }^{68}$ The authors described a case of bile duct leakage following cholecystectomy performed in a difficult condition using coelioscopy; the site and extent of the bile leakage were clearly depicted by mangafodipirenhanced MRCP. Since then, other studies have confirmed the excellent diagnostic performance of this technique. ${ }^{69,70} \mathrm{In}$ a later study, including 11 patients with a suspicion of bile duct leakage, Vittelas et al obtained sensitivity and specificity values of $86 \%$ and $83 \%$ respectively. ${ }^{71}$ One of the limits of mangafodipir-enhanced MRCP is that it may overestimate the degree of bile duct stenosis.

Both vascular and extravascular complications may occur following liver transplantation. ${ }^{72}$ Vascular complications can cause ischemic cholangitis or necrosis of the bile ducts. Mechanical bile duct complications can be of two types: anastomotic stenosis or leakage, and they both require rapid diagnosis for optimal management. In this setting mangafodipir-enhanced MRI is valuable and probably better than the more commonly used heavily T2-weighted fat-suppressed sequences. ${ }^{73,74}$ In a series of 25 transplanted patients, mangafodipir MRCP was superior to conventional $\mathrm{MRCP}$ in the assessment of both biliobiliary and bilioenteric anastomoses $(P<0.001){ }^{72}$

Patients with a bilioenteric anastomosis may develop complications such as bile duct obstruction, cholangitis, stenosis of the intrahepatic ductules, and calculi. However, bilioenteric anastomoses are very difficult to evaluate by conventional MRCP due to the presence of reflux aerobilia that may hinder visualization of the anastomosis and the underlying bile ducts. Morphological studies may be difficult in these conditions because of the orientation and small size of the anastomosis. These limitations can be overcome by using mangafodipir MRCP: the anastomosis can be then well opacified and the study performed using thin 3D T1-weighed sequences. Hottat et $\mathrm{al}^{75}$ demonstrated that mangafodipir enhanced MRCP was able to detect the bilioenteric anastomosis in all the cases, whereas conventional T2-weighted MRI cholangiography detected the anastomosis in only $85 \%$ of cases. MRCP false positives are most frequently due to the superimposition of abdominal fluid over the region of interest. If visualization of the bile ducts is delayed by more than 2.5 to 3 hours then the anastomosis is to be considered obstructed. ${ }^{75}$
Mangafodipir-enhanced MRCP also allows accurate mapping the intrahepatic bile ducts in the normal individual and is useful in the selection of living donors for transplantation. ${ }^{66,67}$

\section{The myocardium}

The myocardial cells actively accumulate manganese ions, in an additive fashion through L-type voltage operated calcium channels in the cell membrane. ${ }^{76-79}$ Animal studies have shown that Mn can be used to identify infarction regions. ${ }^{80-84}$ This is possible because Mn uptake leads to a larger increase in longitudinal relaxation rate (R1) in the normal compared to the necrotic myocardium. ${ }^{79,81,84-86}$ Recent studies also show that Mn uptake is reduced in the "stunned" myocardium. ${ }^{87,88}$ In a study on healthy human volunteers, ${ }^{89}$ a 37\% increase in R1 in left ventricular (LV) myocardium was observed starting from one hour after infusion of a normal liver dose of $5 \mu \mathrm{mol} / \mathrm{kg}$ body weight of mangafodipir. In the same study, only a negligible additional R1 enhancement was achieved by doubling the dose to $10 \mu \mathrm{mol} / \mathrm{kg}$, and $15 \mu \mathrm{mol} / \mathrm{kg}$ yielded no further enhancement. In another study on healthy volunteer,,$^{90} 5$ - and 30 -minute infusions with $5 \mu \mathrm{mol} / \mathrm{kg}$ of MnDPDP yielded equal elevations in R1 in normal LV myocardium. In a recent study, mangafodipir was administered to 10 patients with recent myocardial infarction. ${ }^{91}$ The authors were able to show that a reduced wall thickness was associated with a reduction both in the pre-contrast $\mathrm{R} 1$ and in the contrast enhancement. Furthermore, both remote and infarcted regions showed rapid initial contrast accumulation. Mangafodipir-enhanced MRI may be a promising method to assess the extent of the infarcted myocardium. However, more studies are necessary to confirm these initial results.

\section{Conclusions}

Mangafodipir-enhanced MRI is mainly utilized to detect and characterize focal liver lesions. There is strong evidence that the liver-specific agent increases the sensitivity of MRI in detecting liver metastases and this is useful in selecting patients for liver resection and for surgical planning. Differences between MRI and other imaging techniques, such as MDCT and FDG-PET, are more pronounced when lesions are of small size and following neoadjuvant CHT. Therefore, we believe that MRI with liver-specific agent should be performed routinely in all patients planned for surgery following CHT. Images should be evaluated and reviewed by radiologists with a proven expertise in hepatobiliary diagnostics, and results should be discussed in multidisciplinary 
meetings that involve liver surgeons, medical oncologists, radiologists, and radiation oncologists.

Mangafodipir-enhanced MRI may be useful in selected cases to characterize focal liver or pancreatic lesions that are controversial at conventional imaging. It is of help in distinguishing between liver metastases and FNH, between well and poorly or non-differentiated hepatocellular carcinomas in patients with liver cirrhosis, or between focal pancreatitis and pancreatic cancer. Finally, MRI with the liver-specific agent is occasionally used for a non-invasive assessment of bile duct leakage complicating hepatobiliary surgery.

\section{Disclosures}

The authors declare no conflicts of interest.

\section{References}

1. Reimer P, Schneider G, Schima W. Hepatobiliary contrast agents for contrast-enhanced MRI of the liver: properties, clinical development and applications. Eur Radiol. 2004;14:559-578.

2. Gandhi SN, Brown MB, Wong JG, et al. MR contrast agents for liver imaging: what, when, how. Radiographics. 2006;6(6):1621-1636.

3. Boraschi P, Donati F, Gigoni R, et al. Mangafodipir trisodium-enhanced MR imaging of pancreatic disease. Eur Radiol. 2006;16:988-997.

4. Toft K, Hustvedt SO, Grant D, et al. Metabolism and pharmacokinetics of MnDPDP in man. Acta Radiol. 1997;38:677-689.

5. Elizondo G, Fretz CJ, Stark DD, et al. Preclinical evaluation of Mn-DPDP: new paramagnetic hepatobiliary contrast agent for MR imaging. Radiology. 1991;178:73-78.

6. Ba-Ssalamah A, Uffman M, Saini S, et al. Clinical value of MRI liverspecific contrast agents: a tailored examination for a confident diagnosis of focal liver lesions. Eur Rad. 2009;19:342-357.

7. Ward J, Guthrie JA, Scott DJ, et al. Hepatocellular carcinoma in the cirrhotic liver: double-contrast MR imaging for diagnosis. Radiology. 2000;216:154-162.

8. Akin EB, Vitellas KM, Rajab A, et al. Magnetic resonance cholangiography with mangafodipir trisodium (Teslascan) to evaluate bile duct leaks after T-tube removal in liver transplantation. $J$ Comput Assist Tomogr. 2004;28:613-616.

9. Yoshikawa K, Inoue Y, Akahane M, et al. Phantom and animal studies of a new hepatobiliary agent for MR imaging: comparison of Gd-DTPADeA with Gadoxate. J Magn Reson Imaging. 2003;18: 204-209.

10. Misselwitz B, Weinmann HJ. A toxicologic risk for using manganese complexes? A literature survey of existing data through several medical specialties. Invest Radiol. 1995;30:611-620.

11. Bernardino ME, Young SW, Lee JK, et al. Hepatic MR imaging with Mn-DPDP: safety, image quality, and sensitivity. Radiology. 1992;183:53-58.

12. Wang C, Ahlström H, Ekholm S, et al. Diagnostic efficacy of MnDPDP in MR imaging of the liver. A phase III multicenter study. Acta Radiol. 1997;38:643-649.

13. Padovani B, Lecesne R, Raffaelli C, et al. Tolerability and utility of mangafodipir trisodium injection (MnDPDP) at the dose of $5 \mu \mathrm{mol} / \mathrm{kg}$ body weight in detecting focal liver tumors: results of a phase III trial using an infusion technique. Eur J Radiol. 1996;23:205-211.

14. Benhard C. Safety of mangafodipir administration at abdominal MR imaging: bolus injection vs. slow infusion. Eur Rad. 2002;12:S291.

15. Figueredo A, Rumble RB, Maroun J, et al. Follow-up of patients with curatively resected colorectal cancer: a practice guideline. BMC Cancer. $2003 ; 6: 26$
16. Karabacakoglu A, Adiguzel Y, Karakose S, et al. Characterization of focal liver lesions: use of mangafodipir trisodium (MnDPDP)-enhanced MR images. Turk J Gastroenterol. 2006;17:164-171.

17. Federle MP, Chezmar JL, Rubin DL, et al. Safety and efficacy of mangafodipir trisodium (MnDPDP) injection for hepatic MRI in adults: results of the US multicenter phase III clinical trials. Efficacy of early imaging. J Magn Reson Imaging. 2000;12:689-701.

18. Bartolozzi C, Donati F, Cioni D, et al. Detection of colorectal liver metastases: a prospective multi center trial comparing unenhanced MRI, MnDPDP-enhanced MRI, and spiral CT. Eur Radiol. 2004; 14:14-20.

19. Kim KW, Kim AY, Kim TK, et al. Small $(\leq 2 \mathrm{~cm})$ hepatic lesion in colorectal cancer patients: detection and characterization on mangafodipir trisodium-enhanced MRI. Am J Roentgenol. 2004;14:14-20.

20. Regge D, Campanella D, Anselmetti GC, et al. Diagnostic accuracy of portal phase CT and MRI with Mangafodipir trisodium in detecting liver metastases from colorectal carcinoma. Clin Rad. 2006;61: 338-347.

21. Koh DM, Brown G, Riddell AM, et al. Detection of colorectal hepatic metastases using MnDPDP MR imaging and diffusion-weighted imaging (DWI) alone and in combination. Eur Radiol. 2008;18: 903-910.

22. Sahani DV, Kalva SP, Fischman AJ, et al. Detection of liver metastases from adenocarcinoma of the colon and pancreas. Comparison of MnDPDP liver MRI and whole body FDG PET. Am J Roengenol. 2005; 185:239-246

23. Bismuth $\mathrm{H}$, Adam R, Lévi $\mathrm{F}$, et al. Resection of nonresectable liver metastases from colorectal cancer after neoadjuvant chemotherapy. Ann Surg. 1996;224:509-520.

24. Adam R, Delvart V, Pascal G, et al. Rescue surgery for unresectable colorectal liver metastases downstaged by chemotherapy: a model to predict long-term survival. Ann Surg. 2004;240:644-657.

25. Lubezky N, Metser U, Geva R, et al. The role and limitations of 18-fluoro-2-deoxy-D-glucose positron emission tomography (FDG-PET) scan and computerized tomography (CT) in restaging patients with hepatic colorectal metastases following neoadjuvant chemotherapy: comparison with operative and pathological findings. J Gastrointest Surg. 2007;11:472-478.

26. Gallo T, Cirillo S, Macera A, et al. To compare the diagnostic accuracy of portal-phase CT and MRI with mangafodipir trisodium in detection colorectal carcinoma following neoadjuvant therapy. [oral presentation] - ESGAR, June 23-26, Valencia 2009.

27. Zacherl J, Scheuba C, Imhof M, et al. Current value of intraoperative sonography during surgery for hepatic neoplasms. World J Surg. 2002;26:550-554.

28. Tamandl D, Herberger B, Gruenberger B, et al. Adequate preoperative staging rarely leads to a change of intraoperative strategy in patients undergoing surgery for colorectal cancer liver metastases. Surgery. 2008;143:648-657.

29. Danet IM, Semelka RC, Leonardou P, et al. Spectrum of MRI appearances of untreated metastases of the liver. Am J Roentgenol. 2003; 181:809-817.

30. Hamm B, Vogl TJ, Branding G, et al. Focal liver lesions: MR imaging with Mn-DPDP-initial clinical results in 40 patients. Radiology. 1992;182:167-174.

31. Ba-Ssalamah A, Fakhrai N, Matzek WK, et al. Magnetic resonance imaging of liver malignancies. Top Magn Reson Imaging. 2007;18:445-455.

32. Kim YK, Lee JM, Kim CS. Gadobenate dimeglumine-enhanced liver MR imaging: value of dynamic and delayed imaging for the characterization and detection of focal liver lesions. Eur Radiol. 2004;14:5-13.

33. Ros PR, Freeny PC, Harms SE, et al. Hepatic MR imaging with ferumoxides: a multicenter clinical trial of the safety and efficacy in the detection of focal hepatic lesions. Radiology. 1995;196:481-488.

34. Oudkerk M, Torres CG, Song B, et al. Characterization of liver lesions with mangafodipir trisodium- enhanced MR imaging: multicenter study comparing MR and dual-phase spiral CT. Radiology. 2002;223: $517-524$. 
35. Mathieu D, Coffin C, Kobeiter H, et al. Unexpected MR-T1 enhancement of endocrine liver metastases with mangafodipir. J Magn Reson Imaging. 1999;10:193-195.

36. Lai EC, Lau WY. The continuing challenge of hepatic cancer in Asia. Surgeon. 2005;3:210-215.

37. Mitchell DG. MR imaging of cirrhosis and its complications. Abdom Imaging. 2000;25:455.

38. Taouli B, Losada M, Holland A, et al. Magnetic resonance imaging of hepatocellular carcinoma. Gastroenterology. 2004;127:S144-S152.

39. Vogl TJ, Hamm B, Schnell B, et al. Mn-DPDP enhancement patterns of hepatocellular lesions on MR images. J Magn Reson Imaging. 1993; 3:51-58.

40. Liou J, Lee JK, Borrello JA, et al. Differentiation of hepatomas from nonhepatomatous masses: use of Mn-DPDP-enhanced MR images Magn Reson Imaging. 1994;12:71-79.

41. Murakami T, Baron RL, Peterson MS, et al. Hepatocellular carcinoma: MR imaging with mangafodipir trisodium (Mn-DPDP). Radiology. 1996;200:67-77.

42. Grazioli L, Morana G, Caudana R, et al. Hepatocellular carcinoma Correlation between gadobenate dimeglumine-enhanced MRI and pathologic findings. Invest Radiol. 2000;35:25-34.

43. Scharitzer M, Schima W, Schober E, et al. Characterization of hepatocellular tumors: value of mangafodipir- enhanced magnetic resonance imaging. J Comput Assist Tomogr. 2005;29:181-190.

44. Bartolozzi C, Crocetti L, Lencioni R, et al. Biliary and reticuloendothelial impairment in hepatocarcinogenesis: the diagnostic role of tissue-specific MR contrast media. Eur Radiol. 2007;17: 2519-2530.

45. Frazer C. Imaging of hepatocellular carcinoma. J Gastroenterol Hepatol. 1999;14:750-756.

46. Semelka RC, Worawattanakul S, Kelekis NL, et al. Liver lesion detection, characterization, and effect on patient management: comparison of single-phase spiral CT and current MR techniques J Magn Reson Imaging. 1997;7:1040-1047.

47. Youk JH, Lee JM, Kim CS. MRI for detection of hepatocellular carcinoma: comparison of mangafodipir trisodium and gadopentetate dimeglumine contrast agents. Am J Roentgenol. 2004;183:1049-1054.

48. Murakami T, Baron RL, Federle MP, et al. Cirrhosis of the liver: MR imaging with mangafodipir trisodium (Mn-DPDP). Radiology. 1996;198:567-572.

49. Dodd GD III, Miller WJ, Baron RL, et al. Detection of malignant tumors in end-stage cirrhotic livers: efficacy of sonography as a screening technique. Am J Roentgenol. 1992;159:727-733.

50. Popper H. Pathologic aspects of cirrhosis: a review. Am J Pathol. 1977;87:228-264.

51. Klatskin GCH. Histopathology of the Liver. New York: Oxford University Press; 1993.

52. Reddy KR, Kligerman S, Levi J, et al. Benign and solid tumors of the liver: relationship to sex, age, size of tumors, and outcome. Am Surg. 2001;67:173-178.

53. Soyer P, Dufresne AC, Somveille E, et al. Hepatic cavernous hemangioma: appearance on T2-weighted fast spin-echo MR imaging with and without fat suppression. Am J Roentgenol. 1997;168:461-465.

54. Nguyen BN, Flejou JF, Terris B, et al. Focal nodular hyperplasia of the liver: a comprehensive pathologic study of 305 lesions and recognition of new histologic forms. Am J Surg Pathol. 1999;23:1441-1454.

55. Ba-Ssalamah A, Schima W, Schmook MT, et al. Atypical focal nodular hyperplasia of the liver: imaging features of nonspecific and liverspecific MR contrast agents. Am J Roentgenol. 2002;179:1447-1456.

56. Soe K. Liver Pathology associated with the use of anabolicandrogenic steroids. Liver. 1992;12:73-79.

57. Meissner K. Hemorrhage caused by ruptured liver cell adenoma following long-term oral contraceptives: a case report. Hepatogastroenterology. 1998;45:224-225

58. Craig CPR, Edmonson HA. Atlas of tumor pathology: tumors of the liver and intrahepatic bile ducts. Washington DC: Armed forces Institute of Pathology; 1989.
59. Grazioli L, Morana G, Kirchin MA, et al. Accurate differentiation of focal nodular hyperplasia from hepatic adenoma at gadobenate dimeglumine-enhanced MR imaging: prospective study. Radiology. 2005;236:166-177.

60. Halavaara J, Breuer J, Ayuso C, et al. Liver tumor characterization: comparison between liver-specific gadoxetic acid disodiumenhanced MRI and biphasic CT-a multicenter trial. J Comput Assist Tomogr. 2006;30:345-354.

61. Craig JR, Peters RL, Edmondson HA, et al. Fibrolamellar carcinoma of the liver: a tumor of adolescents and young adults with distinctive clinico-pathologic features. Cancer. 1980;46:372-379.

62. McLarney JK, Rucker PT, Bender GN, et al. Fibrolamellar carcinoma of the liver: radiologic-pathologic correlation. Radiographics. 1999; 19:453-471.

63. Worawattanakul S, Semelka RC, Noone TC, et al. Cholangiocarcinoma: spectrum of appearances on MR images using current techniques. Magn Reson Imaging. 1998;16:993-1003.

64. Schima W, Fugger R. Evaluation of focal pancreatic masses: comparison of mangafodipir-enhanced MR imaging and contrast-enhanced helical CT. Eur Radiol. 2002;12:2998-3008.

65. Warshaw AL, Gu Z, Wittenberg J, et al. Preoperative staging and assessment of resectability of pancreatic cancer. Arch Surg. 1990;125:230-233.

66. Kamaoui I, Milot L, Durieux M, et al. Value of MRCP with mangafodipir trisodium (Teslascan) injection in the diagnosis and management of bile leaks. J Radiol. 2007;88:1881-1886.

67. Laurent V, Corby S, Barbary C, et al. New possibilities to study biliary tree and gallbladder: functional magnetic resonance cholangiography contrast-enhanced with mangafodipir trisodium (Mn-DPDP). J Radiol. 2007;88:531-540.

68. Vitellas KM, El-Dieb A, Vaswani K, et al. Detection of bile duct leaks using mr cholangiography with mangafodipir trisodium $\left(\right.$ Teslascan $\left.^{\mathbb{B}}\right)$. J Comput Assist Tomogr. 2001;25:102-105.

69. Park MS, Kim KW, Yu JS. et al. Early biliary complications of laparoscopic cholecystectomy: evaluation on T2-weighted MR cholangiography in conjunction with mangafodipir trisodiumenhanced 3D T1-weighted MR cholangiography. Am J Roentgenol. 2004;183:1559-1566.

70. Aduna M, Larena JA, Martin D, et al. Bile duct leaks after laparoscopic cholecystectomy: value of contrast-enhanced MRCP. Abdom Imaging 2005;30:480-487.

71. Vitellas KM, El-Dieb A, Vaswani K, et al. Using contrast-enhanced MR cholangiography with iv mangafodipir trisodium (teslascan*) to evaluate bile duct leaks after cholecystectomy: a prospective study of 11 patients. Am J Roentgenol. 2002;179:409-416.

72. Pandharipande PV, Lee VS, Morgan GR, et al. Vascular and extravascular complications of liver transplantation: comprehensive evaluation with three-dimensional contrast-enhanced volumetric MR imaging and MR cholangiopancreatography. Am J Roentgenol. 2001;177: 1101-1117.

73. Bridges MD, May GR, Harnois DM. Diagnosing biliary complications of orthotopic liver transplantation with mangafodipir trisodiumenhanced MR cholangiography: comparison with conventional MR cholangiography. Am J Roentgenol. 2004;182:1497-1504.

74. Baris AE, Vitellas KM, Rajab A, et al. Magnetic resonance cholangiography with mangafodipir trisodium (Teslascan) to evaluate bile duct leaks after T-tube removal in liver transplantation. $J$ Comput Assist Tomogr. 2004;28:613-616.

75. Hottat N, Winant E, Metens T, et al. MR cholangiography with manganese dipyridoxyl diphosphate in the evaluation of biliaryenteric anastomoses: preliminary experience. Am J Roentgenol. 2005;184: 1556-1562.

76. Brurok H, Schjott J, Berg K, et al. Manganese and the heart: acute cardiodepression and myocardial accumulation of manganese. Acta Physiol Scand. 1997;159:33-40.

77. Hu TC, Pautler RG, MacGowan GA, et al. Manganese-enhanced MRI of mouse heart during changes in inotropy. Magn Reson Med. 2001;46:884-890. 
78. Hunter DR, Haworth RA, Berkoff HA. Cellular manganese uptake by the isolated perfused rat heart: a probe for the sarcolemma calcium channel. J Mol Cell Cardiol. 1981;13:823-832.

79. Nordhoy W, Anthonsen HW, Bruvold M, et al. Manganese ions as intracellular contrast agents: proton relaxation and calcium interactions in rat myocardium. NMR Biomed. 2003;16:82-95.

80. Brady TJ, Goldman MR, Pykett IL, et al. Proton nuclear magnetic resonance imaging of regionally ischemic canine hearts: effect of paramagnetic proton signal enhancement. Radiology. 1982;144:343-347.

81. Bremerich J, Saeed M, Arheden H, et al. Normal and infarcted myocardium: differentiation with cellular uptake of manganese at MR imaging in a rat model. Radiology. 2000;216:524-530.

82. Goldman MR, Brady TJ, Pykett IL, et al. Quantification of experimental myocardial infarction using nuclear magnetic resonance imaging and paramagnetic ion contrast enhancement in excised canine hearts. Circulation. 1982;66:1012-1016.

83. Schaefer S, Lange RA, Kulkarni PV, et al. In vivo nuclear magnetic resonance imaging of myocardial perfusion using the paramagnetic contrast agent manganese gluconate. J Am Coll Cardiol. 1989;14:472-480.

84. Wendland MF, Saeed M, Bremerich J, et al. Thallium-like test for myocardial viability with MnDPDP-enhanced MRI. Acad Radiol. 2002;9:S82-S83.
85. Brurok H, Skoglund T, Berg K, et al. Myocardial manganese elevation and proton relaxivity enhancement with manganese dipyridoxyl diphosphate. Ex vivo assessments in normally perfused and ischemic guinea pig hearts. NMR Biomed. 1999;12:364-372.

86. Southon TE, Grant D, Bjornerud A, et al. NMR relaxation studies with MnDPDP. Acta Radiol. 1997;38:708-716.

87. Kim TH, Yang DH, Choi JW, et al. Manganese dipyridoxyl diphosphate (MnDPDP)-enhanced magnetic resonance imaging of acute reperfused myocardial injury in a cat model. Part I: Comparison with pathologic examination. Invest Radiol. 2005;40:49-55.

88. Krombach GA, Saeed M, Higgins CB, et al. Contrast-enhanced MR delineation of stunned myocardium with administration of $\mathrm{MnCl}(2)$ in rats. Radiology. 2004;230:183-190.

89. Skjold A, Vangberg TR, Kristoffersen A, et al. Relaxation enhancing properties of MnDPDP in human myocardium. JMagn Reson Imaging. 2004;20:948-952.

90. Skjold A, Kristoffersen A, Vangberg TR, et al. An apparent unidirectional influx constant for manganese as a measure of myocardial calcium channel activity. J Magn Reson Imaging. 2006;24:1047-1055.

91. Skjold A, Amundsen BH, Wiseth R, et al. Manganese dipyridoxyldiphosphate (MnDPDP) as a viability marker in patients with myocardial infarction. J Magn Reson Imaging. 2007;26:720-727.
Reports in Medical Imaging

\section{Publish your work in this journal}

Reports in Medical Imaging is an international, peer-reviewed, open access journal publishing original research, reports, reviews and commentaries on all areas of medical imaging. The manuscript management system is completely online and includes a very quick and fair peer-review system, which is all easy to use.

\section{Dovepress}

Visit http://www.dovepress.com/testimonials.php to read real quotes from published authors. 